\title{
Development of a Novel Charging Algorithm for On-board ESS in DC Train through Weight Modification
}

\author{
Byungdoo Jung*, Hyun Kim**, Heechan Kang** and Hansang Lee ${ }^{\dagger}$
}

\begin{abstract}
Owing to the reduction in the peak power of a DC railway subsystem, many studies on energy storage system (ESS) applications have received attention. Each application focuses on improving the efficiency and addressing regulation issues by utilizing the huge regenerative energy generated by braking-phase vehicles. The ESS applications are widely divided into installation on a vehicle or in a substation, depending on the target system characteristics. As the main purpose of the ESS application is to reduce the peak power of starting-phase vehicles, an optimized ESS utilization can be achieved by the operating at the highest peak power section. However, the weight of an entire vehicle, including those of the passengers, continuously changes during operation; thus, considering the total power consumption and the discharging point is difficult. As a contribution to the various storage device algorithms, this study deals with ESS on board vehicles and introduces an ESS operating plan for peak-power reduction by investigating the weight of a train on a real-time basis. This process is performed using a train-performance simulator, and the simulation accuracy can be increased because the weight in each phase can be adopted in the simulation.
\end{abstract}

Keywords: DC electric railway, Energy storage system, Regenerative energy, Braking power, Train performance

\section{Introduction}

To find an appropriate solution to high energy consumption, many industrial sectors consider technical applications by utilizing available and wasted power. Moreover, carbon dioxide emission and increase in gasoline prices lead to concerns in the transportation system. The electric railway system is the most suitable transportation system where power efficiency can be improved because of its large power consumption pattern and unique operating characteristics. Power fluctuation includes the load variation, which means that an electric vehicle contains variable loads that consume positive power on acceleration and negative power on braking [1-2]. The regenerative energy, which is generated during the breaking phase, is one of the most promising sources of energy savings to system operators. These energy sources are also available in the starting phase, but they are wasted if no suitable vehicles are in the vicinity. Therefore, various methods have been developed and technical applications based on the existing configuration for energy utilization have continuously received attention [3-4]. Among the various power system applications, an energy storage system (ESS) is one of the most efficient types of equipment. Moreover, a DC railway

$\dagger \quad$ Corresponding Author: School of Electrical and Railway Engineering, Kyungil University, Korea. (hslee80@kiu.ac.kr)

* Dept. of Transportation Engineering, Keimyung University, Korea. (jungbd@kmu.ac.kr)

** Dept. of Railway Research, The Korea Transport Institute, Korea (\{hyun kim, hckang\}@koti.re.kr)

Received: Received: May 30, 2014; Accepted: September 4, 2014 system has unique motion characteristics and power consumption pattern depending on the vehicle operating plan. Therefore, the operation and management process can be handled easily compared with other ESS applications. To improve the efficiency of a DC railway system, ESS applications have been developed in various directions. Through integration with a supercapacitor, which has a fast response characteristic, huge amount of wasted regenerative energy can be reused in other phases in largescale railway power networks [5-7]. Several studies that utilized regenerative energy through ESS integration have been conducted, namely, ESS types, control strategies, and charging algorithms [8-10]. Regarding the installation site, equipping the vehicles or the substation with an ESS has been primarily considered. Because of the pros and cons of the each integration methods in terms of system loss and charging/discharging efficiency, the installation site depends on the characteristics of a targeted system [11].

ESS management algorithms regarding DC railway systems are continuously developed. As the accuracy of Train Performance Simulator (TPS) have been upgraded through improving process recently, the application of energy storage system by using the simulator is continuously increasing. However, optimizing the energy discharge point to reduce the peak power is difficult because the present TPS cannot consider the precise weight because of the variability of passenger information in a specific vehicle, which is difficult to verify by the system operator. Thus, the power consumption curves that determine the starting point of ESS discharge is difficult to optimize on a real- 
time basis.

This article focuses on the optimization of peak-power reduction using an ESS, which is specialized for regenerative energy [12-13]. The developed algorithm mainly considers vehicles equipped with ESS devices that usually use regenerative energy as power for self-operation. The optimization process deals with updating the weight information of each train in the TPS when generating the power consumption curve used to modify the charging point for ESS operation. By using this updating process to check the ESS operation point, the TPS can more realistically generate the power curve, and the ESS can perform at an optimized point for peak-power reduction.

In Section 2, we discuss the series of research activities and the system basic formulas. In Section 3, we introduce the main idea regarding the weight updating plan relative to the train performance and the application methods used in the simulation. In Section 4, we present the simulation of a Korean electric railroad system, which is configured for a low-voltage DC system. We analyze the experimental results in Section 5.

\section{Characteristics of Electric Railway Systems}

\subsection{Standard operating plan}

The DC railway system, especially the urban subway system, generally operates according to the train operating plan, which is planned ahead [14]. Through the TPS, the optimized movement patterns in each location are normally matched with real operation except in abnormal cases. In addition, the errors between the expected movement and the real operation continuously decreased, and operating plans on unmanned railway system are being designed by applying the simulator. Fig. 1 shows the movement of vehicles planned by the TPS, which is allocated in one line. Each vehicle operates according to an operating plan in a specific headway. A vehicle should be at its designated location at the designated time. Although a possible train velocity variation can occur, a standardized pattern of acceleration exists as well as the relevant power consumption at each point. Therefore, on the basis of the information on each vehicle, the vehicle movement can be standardized, and the power consumption curve of a specific vehicle can be estimated using the motion pattern at a certain point. The TPS calculates the electrical traction drive of each vehicle on the basis of the input data, and the power supply in each substation can be estimated through a power-flow analysis. In a previous study, power-flow analysis was performed to check the power consumption at each substation, and the peak-power measurement or the operation of energy storage devices could be simulated for system research [15-16]. However, the simulation process was disabled in checking the weight variation at each station; thus, the ESS optimization process was difficult

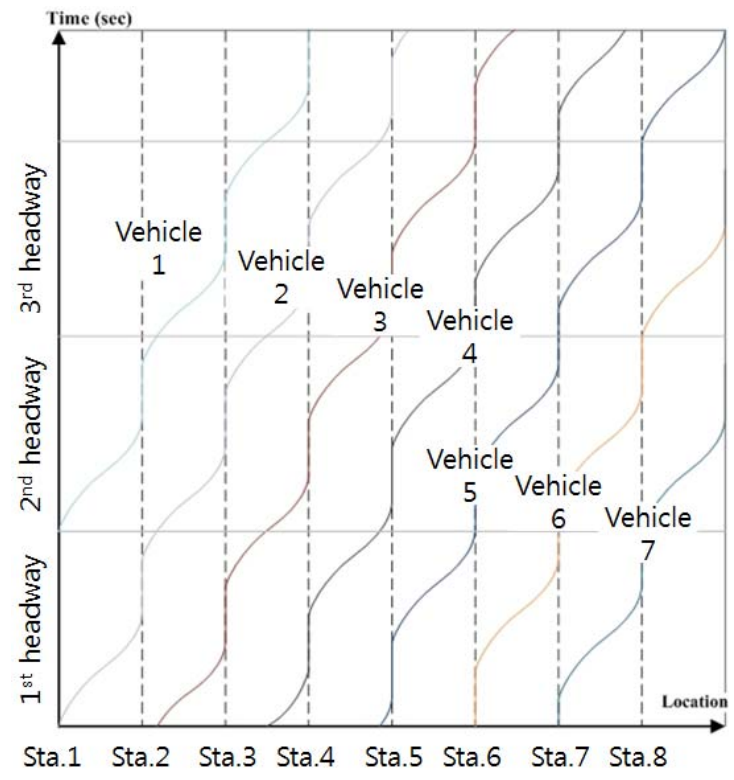

Fig. 1. Vehicle location during each headway

because of the inexactitude of the power consumption pattern. To improve this simulation, a new algorithm is required that includes a weight updating process to generate an accurate power consumption curve by interworking with the TPS system.

\subsection{Irregular power consumption}

Fig. 2 shows the motion and power consumption patterns according to the train operating plan. The power supplied at a certain point is transferred to each vehicle using a diode rectifier adopted in the substation. However, the regenerative energy cannot be transferred to the utility grid in the absence of specific devices such as a regeneration inverter. Previous DC railway systems used the regenerative energy to accelerate other vehicles, but they suffered from the uncertainty of existing vehicles in the vicinity, and electricity transfer to other vehicles could generate system loss, which made the system voltage higher than that at the normal phase. To solve this problem, an on-board ESS is required (which prevents a regenerative output into the electricity system through catenary) and an appropriate operating plan that could reflect the weight

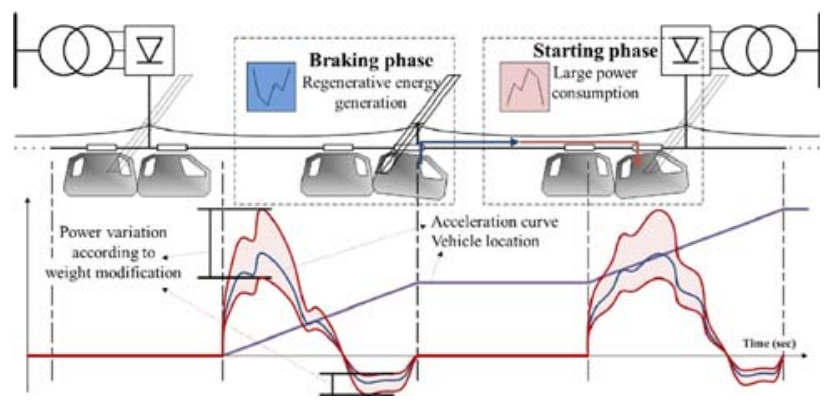

Fig. 2. Power consumption variation by weight change at each phase 
validation of the vehicles. To consider the latter, an equation generally applied to vehicles is proposed and implemented in the inverse calculation processes.

The power consumption pattern can be standardized according to the acceleration and weight of the vehicles. The acceleration of the vehicles is related to the traction power of the motors and the operating resistance of several vehicles, which is related to the dynamic mass traction. The expression for the traction power of a vehicle considering the effective traction power is shown in (1).

$$
F_{d}=F_{a}+R_{r}+R_{c} \pm R_{g}
$$

where, $F_{d}$ is the traction power of the vehicle

$F_{a}$ is the acceleration power

$R_{r}$ is the resistance of the drive

$R_{C}$ is the resistance of the curve

$R_{g}$ is the resistance of the gradient.

To present separately the power consumption pattern into the operation algorithm, the vehicle operating modes are mathematically divided into three modes: acceleration, regenerative, and fixed-speed modes. The motor consumes the supplied energy from the ESS when the vehicle starts. When regenerative energy is generated during deceleration, this energy is stored in the ESS. In the fixed-speed mode, the energy consumption is calculated depending on the driving conditions of the vehicle and its speed. Driving conditions include the road conditions, i.e., whether the course is sloping or flat.

The input energy formula of the motor is shown in (2).

$$
E_{\text {in }}=\frac{F_{d} \times W \times v \times g_{\text {gravity }} \times \eta_{\text {gear }} \times \eta_{\text {motor }} \times p f_{\text {motor }}}{N_{\text {motor }} \times 3600}
$$

where, $W$ is the dynamic weight of the vehicle

$$
\begin{aligned}
& g_{\text {gravity }} \text { is the acceleration due to gravity } \\
& n_{\text {gear }} \text { is the gear efficiency } \\
& n_{\text {motor }} \text { is the motor efficiency } \\
& p f_{\text {motor }} \text { is the motor power factor. }
\end{aligned}
$$

When the vehicle is in the regenerative mode, the motor produces regenerative energy and supplies this energy to the vehicle. The regenerative energy formula of the motor is shown in (3).

$$
E_{r e}=\frac{F_{b} \times W \times v \times g_{\text {gravity }} \times \eta_{\text {gear }} \times \eta_{\text {motor }}}{N_{\text {motor }} \times p f_{\text {motor }} \times 3600}
$$

In this study, the power consumption and regenerative energy of the electric vehicles are calculated using the above formulas. Furthermore, the weight updating algorithm is also configured and implemented by the simulation process by applying the equation in reverse. The power consumption and the charging power following every time variation (measurable information and calculated values) are calculated.

\subsection{Electric traction with On-board ESS}

Generally, railway traction systems configure the overhead contact lines to transfer electrical power through a catenary interconnected to a substation system. This subsystem requires electrical power from a utility grid according to the system specifications (either in DC or AC) with the required voltage level. Typical urban railway systems adopt a DC system, and in the case of low-voltage application of on-board energy storage devices, this system must employ additional DC-DC power converters, as shown in Fig. 3, which demonstrates the concept of the proposed system.

The simulation cases presented in this paper used an supercapacitor for the ESS, which has a low internal resistance and permits high charging-/discharging-cycle efficiency. From the above formulas, the regenerative energy generated in the breaking mode can be saved in the supercapacitor devices and transferred to the electric motor system in the next acceleration mode. To apply the proposed algorithm, the supercapacitor should be designed according to the supercapacitor design formulas that optimize the regenerative energy. The supercapacitor size that optimizes the regenerative energy can be represented by the maximum speed of the vehicles, which is related to the maximum storable energy. In addition, the efficiency values of the mechanical and electrical traction should be included in (4).

$$
E_{S C}=\frac{1}{2} \eta_{\text {mech }} \cdot \eta_{\text {motor }} \cdot \eta_{\text {inv }} \cdot \eta_{\text {con }} \cdot \eta_{S C} \cdot W_{\text {veh }} \cdot v_{\max }^{2}
$$

where, $n_{\text {mech }}$ is the mechanical transmission efficiency

$n_{\text {motor }}$ is the motor efficiency

$n_{i n v}$ is the inverter efficiency

$n_{c o n}$ is the DC-DC converter efficiency

$n_{S C}$ is the supercapacitor module efficiency

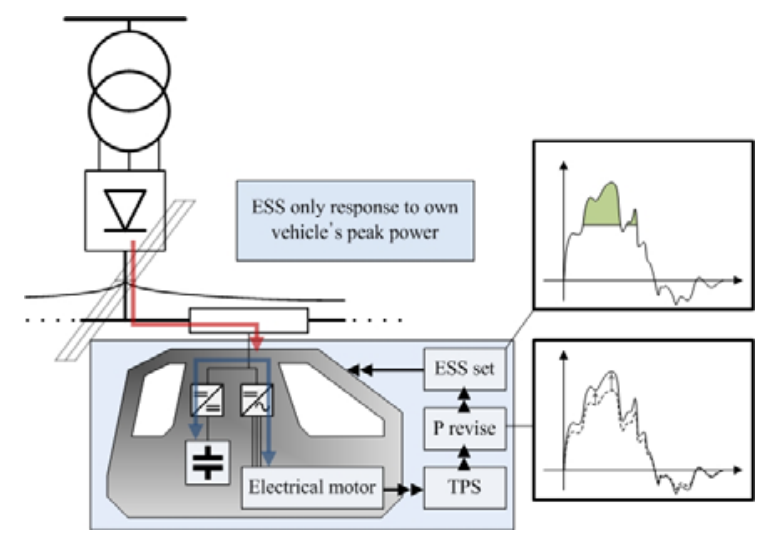

Fig. 3. Weight modification process using TPS 
$W_{v e h}$ is the weight of the fully loaded vehicle

$v_{\max }$ is the maximum speed of the vehicle.

The differential values of the maximum speed of the vehicle are applied in configuring the power converter system to absorb the highest regenerative energy during operation. The maximum regenerative power can be calculated by (5).

$$
P_{S C}=\eta_{\text {mech }} \cdot \eta_{\text {motor }} \cdot \eta_{\text {inv }} \cdot \eta_{\text {con }} \cdot W_{\text {veh }} \cdot d_{\text {max }} \cdot v_{\max }
$$

where $d_{\max }$ is the maximum deceleration rate.

The calculated capacity of supercapacitor is composed of a series of data according to the selected commercial system data. The designed supercapacitor modules are installed in each vehicle and interconnected with the electrical system through a DC-DC converter. The module stores the regenerative energy and only shares power with its own electric motor during acceleration. The supercapacitor discharging process is implemented according to the signal designated beforehand by the proposed updating plan. Because the power consumption of the TPS changes with the total weight of the vehicle, the signal is also modified at each phase according to the variation of the passenger information. The supercapacitor system checks the consumed power information at each phase and supplies energy when the measured instantaneous power exceeds a set point. The weight value of the supercapacitor modules must also be considered in the simulation process for accuracy.

\subsection{Peak power reduction}

The main purpose of the ESS in the railway system is to compensate the peak power using the stored regenerative energy during the braking mode. The substation system in the railway measures the peak power at every specific time interval to estimate the basic electricity cost, which is approximately $25 \%$ of the overall railway electricity cost. Reducing the peak power can reduce the operating costs and can benefit from voltage regulation.

To reduce the peak power of the substation, the on-board ESS should focus on its highest power consumption because the peak power of the substation mainly depends on the vehicle power consumption. Therefore, the algorithm should find the reference value of the active power to support the required power of the traction system at designated phases.

\section{Strategy Development}

\subsection{Weight calculation process}

In the TPS, the required energy for each phase is calculated to check the substation supply. On the basis of the system configuration, the required power of the vehicle and the power consumption curve can be generated by the TPS, and these data can be used as reliable information to predict the power consumption of the vehicles. Using this information, the supercapacitor can operate at an optimized starting point of discharging the saved energy; however, the additional information about the vehicle should be modified to reduce the error between the real power consumption and that of the simulation. To operate the supercapacitor at a specific point of active power, this study focuses on the reverse calculation process to obtain the weight information. The vehicle operating system checks the consumed power of the electric motors at every phase and sends the information to the TPS, along with the other operating information. Subsequently, the active power curve prediction system calculates the acceleration power curve by considering the variable factors, including the weight information. The modified formula is introduced in (6).

$$
W=\frac{E_{\text {in }} \times N_{\text {motor }} \times 3600}{F_{d} \times v \times g_{\text {gravity }} \times \eta_{\text {gear }} \times \eta_{\text {motor }} \times p f_{\text {motor }}}
$$

To use the equation for updating the weight data, every variable that composes the weight value should be modified. The input energy can then be represented by (7).

$$
E_{\text {in }}=\frac{P \times \eta_{d} \times \eta_{\text {motor }} \times 367}{N_{\text {motor }} \times t}
$$

where, $n_{d}$ is the power transmission efficiency.

Using this conversion process, the updating process can use the instantaneous power, which can be measured at each phase by the system operator. Therefore, the updating process can be shortened by removing the energy calculation process. To change the traction power variables, the acceleration formula, including the traction power, is introduced in (8).

$$
A=\frac{\left(F_{d}-R_{r} \pm R_{g}-R_{c}\right)}{28.35 \cdot(1+x) \cdot W}
$$

where, $x$ is the inertia coefficient.

The traction power variable is dependent on the weight; thus, the revised formula should transform this value. In (8), the other values can be used as parameters in the calculation process except the weight and acceleration. Eq. (6) is transformed to (9) using (8).

$$
\begin{array}{r}
28.35 \cdot A \cdot(1+x) W^{2}+\left(R_{r} \pm R_{g}+R_{c}\right) W \\
-\frac{P \times \eta_{d} \times 367 \times 3600}{v \times g_{\text {gravity }} \times \eta_{\text {gear }} \times p f_{\text {motor }} \times t}=0
\end{array}
$$

This quadratic equation inserts the algorithm and calculates the weight at every required situation. The 
required situation is detected by checking the instantaneous power, and a modification process is implemented according to the operating signal.

\subsection{Verification process using the state of charge}

To appropriately consider the storage device condition, the state of charge (SOC) of the supercapacitor should be calculated every second by integrating the vehicle power consumption. When the SOC is attained, the supercapacitor cannot operate further. In addition, the SOC of the supercapacitor cannot exceed a certain operating point because of its life cycle. Because this study focuses on the active power of a certain vehicle, the SOC variation is mainly applied to the adopted vehicle and follows the data flow outlined below.

The discharging process is implemented on a designated time by the calculation process. In the discharging process, the SOC information is used to generate the reference power signal, which is the highest power consumption of the vehicle. The available SOC for the discharging process is compared with the integral values between the reference power and the expected power consumption.

Normally, the charging process is carried out on every regenerative mode; however, the unexpected SOC variation must be checked whether it is above or below a set point, and the information is transferred to the TPS. Because the system focuses on the predicted values, revision processes must be designed in every way possible.

The SOC can also be affected by voltage fluctuation. The change in the instantaneous current due to voltage fluctuation should be compensated by the surplus SOC. The simulation process should also consider the fluctuation in the vehicle operation. The voltage and current of the vehicle is represented by (10) and (11).

$$
V_{\text {motor }}=V_{c a t} \times \frac{\sqrt{6}}{\pi}
$$

where, $V_{c a t}$ is the voltage at the catenary.

$$
i_{\text {motor }}=\frac{E_{\text {in }}}{\sqrt{6} \cdot V_{\text {cat }}}
$$

To verify the excess power, the SOC of the supercapacitor should be checked during operation. The prephase SOC should be considered at every second. The SOC of the supercapacitor is described in (12).

$$
\operatorname{SOC}(t+1)= \begin{cases}\operatorname{SOC}(t)-\frac{E_{i n}(t)}{\eta E_{\max }} & \left(P_{S C}(t) \geq 0\right) \\ \operatorname{SOC}(t)+\frac{\eta E_{r e}(t)}{E_{\max }} & \left(P_{S C}(t)<0\right)\end{cases}
$$

where, $P_{S C}$ is the output power of the supercapacitor and $E_{\text {max }}$ is the maximum electrical energy of the supercapacitor.
The regenerative energy is expressed by (13).

$$
E_{r e}=\frac{P_{r e} \times 367}{\eta_{d} \times \eta_{\text {motor }} \times N_{\text {motor }} \times t}
$$

The weight variations also derive regenerative energy variation so it must be included in the curve generating process. By weight updating process, the expected regenerative energy is recalculated and be directly applied to generate following power reference signal.

\subsection{Composing the charging algorithm}

The flowchart of the supercapacitor operating plan and charging / discharging process, which takes into account the weight calculation process, is shown in Fig. 4. As the

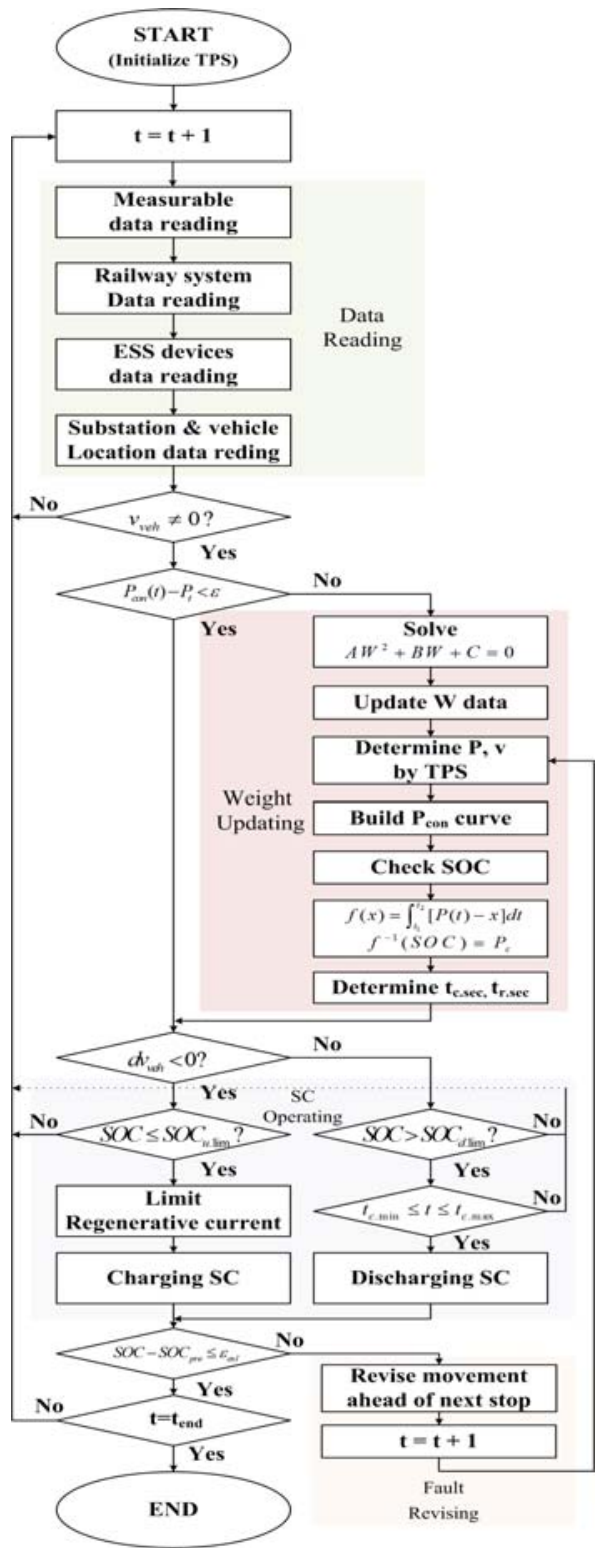

Fig. 4. Flowchart of the weight update and supercapacitor operation 
vehicles are operated at a fixed headway, the algorithm implements each process by assuming a predicted movement. The algorithm should share the predicted value with the TPS of the main signal generator and should lower the possible error relative to the acceptable limit.

First, the algorithm collects the system operation data, including the measurable data of each vehicle and the railway system specifications such as the line resistance and substation distance. The system operation data mainly depend on the TPS output data. As mentioned earlier, the TPS calculates the vehicle location and power consumption on the basis of the vehicle information and headway, which is predetermined as a set value. In this algorithm, the TPS calculates the main data at the initial state using typical information on the basis of an empty vehicle. Using the data reading process, the comparison process is started. If a variation exists between the expected power consumption and the measured power at the vehicle, the algorithm checks the degree of variation and determines whether the updating process has started or not.

The weight updating process is initialized by solving the quadratic equation. Using the output value, the TPS can generate the updated information such as power consumption curves and expected location of the vehicle. The generated power curve can be revised during the starting phase because the passenger weight might be changed during the starting phase. Subsequently, the point-generating process for discharging during the acceleration phase is implemented using the expected power consumption curve. Following the available residual energy of the SC, the algorithm determines the point where the vehicles use energy both from the utility power grid and the saved energy in the SC. To be exact, the algorithm sets the starting and stopping times of the discharge. Furthermore, the algorithm checks the regenerative energy so that it can be used in the reverse process, which is included in the next state of the algorithm.

The information that determines the aforementioned state is transferred to the supercapacitor operating process after the vehicle operating mode is checked. If the saved energy is not above / below the upper / lower limit, each process proceeds according to the preset order. The regenerative energy can be stored in the ESS regardless of the time signal, but the discharging process considers the time signal, which is determined in the above process. After the suitability of the time signal for peak-power reduction is checked, the discharging process can proceed. Because this on-board system focuses on utilizing the regenerative energy for its own vehicle, the charging process suffers from limitations because of the possibility of releasing regenerative energy to the catenary.

Although the urban railway system generally operates according to a plan, the system can possibly experience unexpected situations and requires a revision process. In this algorithm, the revision process is included to consider these situations on the basis of a specific vehicle location at a designated time. If some changes occur because of unexpected deceleration or stops, the process revises the vehicle operating plan and changes the predicted value at the next stage through the TPS.

\section{Simulation Configuration}

\subsection{Target line information}

The main purpose of the simulation is to develop an appropriate operation of the on-board ESS using the proposed algorithm. The Gwang-ju Metro Line 1 has a relatively high headway, which is suitable for an on-board supercapacitor energy storage system. The Gwng-ju Metro Line 1 is composed of 14 stations and four substations with fixed distances, as shown in Fig. 5. The system information used in the calculation and simulation is shown in Table 1.

\subsection{On-board suitability}

The target line operates with a 600 -s non-peak headway. Fig. 1 shows that each vehicle operates according to the operating plan, and the first vehicle in the up and down lines leaves from the end of the route. Because the line operates only two vehicles in each direction, the possibility of sharing the regenerative energy during the breaking mode of a specific vehicle is low. Furthermore, the on-

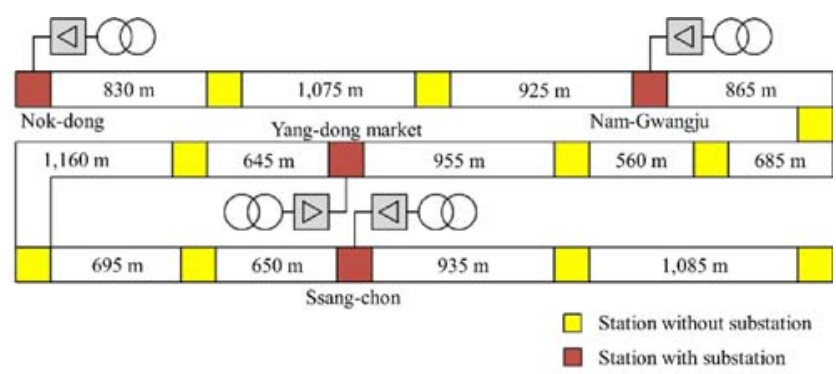

Fig. 5. Gwang-ju Metro Line 1 location map

Table 1. System conditions of Gwang-ju Metro Line 1

\begin{tabular}{|c|c|c|}
\hline \multicolumn{2}{|c|}{ Parameter category } & Value \\
\hline \multicolumn{2}{|c|}{ Rated voltage } & $1,500[\mathrm{~V}]$ \\
\hline \multicolumn{2}{|c|}{ Maximum velocity } & $80[\mathrm{~km} / \mathrm{h}]$ \\
\hline \multicolumn{2}{|c|}{ Maximum acceleration } & $3.0[\mathrm{~km} / \mathrm{h} / \mathrm{s}]$ \\
\hline \multicolumn{2}{|c|}{ Maximum deceleration } & $3.5[\mathrm{~km} / \mathrm{h} / \mathrm{s}]$ \\
\hline \multicolumn{2}{|c|}{ Stop time } & $30[\mathrm{~s}]$ \\
\hline \multicolumn{2}{|c|}{ Headway } & $600[\mathrm{~s}]$ \\
\hline \multicolumn{2}{|c|}{ Operating vehicles } & 2 \\
\hline \multicolumn{2}{|c|}{ Source impedance } & $0.02956[\Omega]$ \\
\hline \multirow{4}{*}{$\begin{array}{l}\text { Substation } \\
\text { location }\end{array}$} & Nok-dong & $0[\mathrm{~m}]$ \\
\hline & Nam-Gwangju & $2,830[\mathrm{~m}]$ \\
\hline & Yang-dong & $5,895[\mathrm{~m}]$ \\
\hline & Ssang-chon & $9,045[\mathrm{~m}]$ \\
\hline \multicolumn{2}{|c|}{ Feeder impedance } & $0.0203[\Omega / \mathrm{km}]$ \\
\hline \multicolumn{2}{|c|}{ Rail impedance } & $0.000464[\Omega / \mathrm{km}]$ \\
\hline
\end{tabular}


Table 2. Numerical data of the maxwell BMOD0063 P125 supercapacitor module

\begin{tabular}{c|c}
\hline Parameter category & Data information \\
\hline Rated voltage & $125[\mathrm{~V}]$ \\
\hline Rated capacitance & $63[\mathrm{~V}]$ \\
\hline Maximum series voltage & $1500[\mathrm{~V}]$ \\
\hline Maximum continuous current & $140[\mathrm{~A}]$ \\
\hline Stored energy & $136.7[\mathrm{~W} \cdot \mathrm{h}]$ \\
\hline Mass, typical & $60.5[\mathrm{~kg}]$ \\
\hline
\end{tabular}

board system should consider the economic feasibility; the Gwang-ju Metro Line 1 is suited for an on-board system because of the low construction cost of the vehicles. In this study, the storage system is designed using a commercial supercapacitor module, which can manage $1500 \mathrm{~V}$ by implementing the module in series. Table 2 presents the numerical values used in the simulation. The additional mass of the storage system is also considered using the numerical value of the reference.

\subsection{Circuit modeling}

The system is evaluated using PSCAD simulation by using Fortran language. Fig. 6 shows the developed circuit by PSCAD from the data flowchart mentioned in the previous section. The substation is constructed using a diode configuration, and the line data are considered on

Table 3. Numerical data of the performed simulation

\begin{tabular}{c|c|c|c}
\hline Data & Value & Data & Value \\
\hline $\mathrm{W}_{\mathrm{T}}$ & $30.9[\mathrm{ton}]$ & $\mathrm{g}_{\text {gravity }}$ & $9.81\left[\mathrm{~m} / \mathrm{s}^{2}\right]$ \\
\hline $\mathrm{W}_{\mathrm{M}}$ & $31.9[\mathrm{ton}]$ & $\mathrm{n}_{\text {gear }}$ & 0.98 \\
\hline $\mathrm{W}_{\mathrm{SC}}$ & $4.903[\mathrm{ton}]$ & $\mathrm{n}_{\text {motor }}$ & 0.95 \\
\hline $\mathrm{m}$ & $80[\mathrm{~kg}]$ & $\mathrm{n}_{\mathrm{SC}}$ & 0.95 \\
\hline $\mathrm{W}_{\text {full }}$ & $168.323[\mathrm{ton}]$ & $\mathrm{n}_{\text {con }}$ & 0.92 \\
\hline $\mathrm{C}_{\text {rate }}$ & $8.64[\mathrm{kWh}]$ & $\mathrm{n}_{\text {inv }}$ & 0.92 \\
\hline Power & $3,048[\mathrm{~kW}]$ & $\mathrm{pf}_{\text {motor }}$ & 0.98 \\
\hline SOC $_{\text {init }}$ & 0.4 & &
\end{tabular}

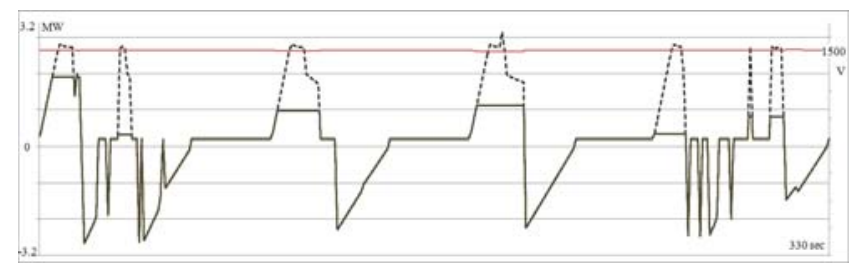

Fig. 7. Power consumption curve and voltage fluctuation under normal operation (North-bound)

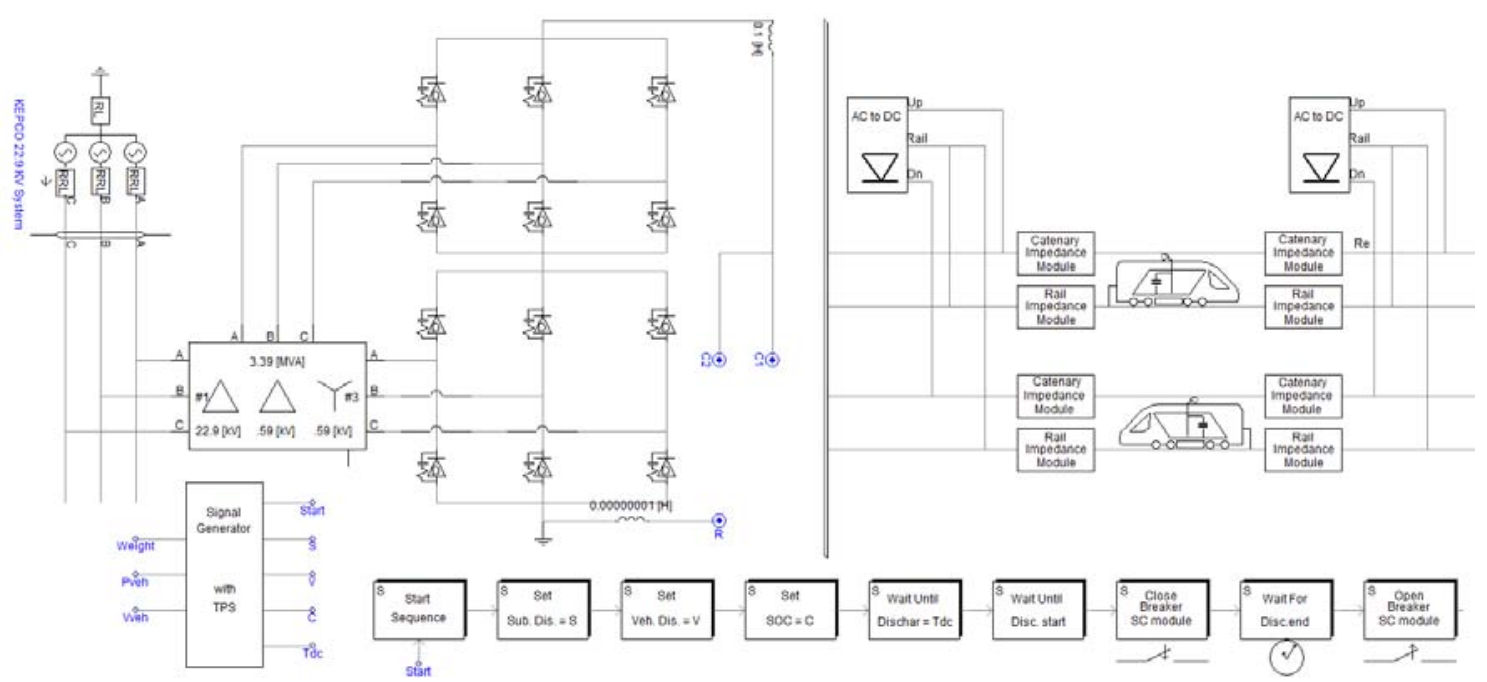

Fig. 6. Simulated operating structure developed by PSCAD 


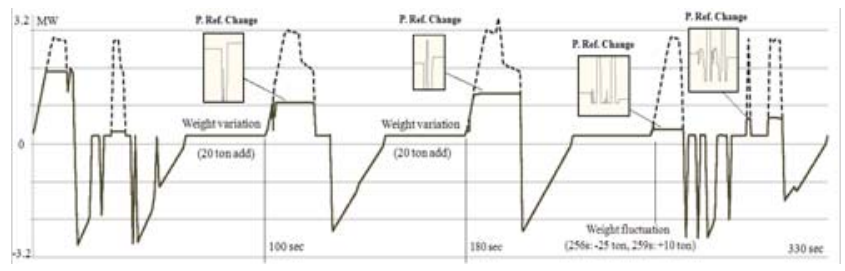

Fig. 8. Power consumption curve and reference signal change with weight variation (North-bound)

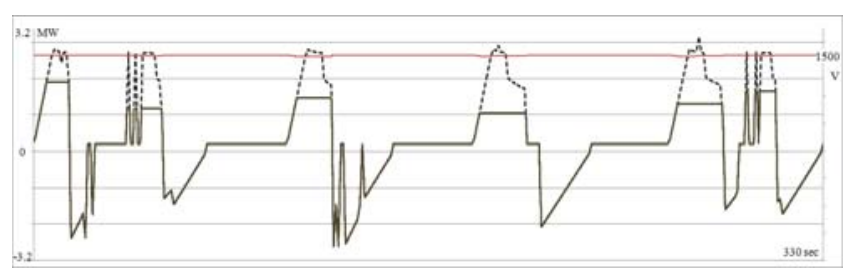

Fig. 9. Power consumption curve and voltage fluctuation under normal operation (South-bound)

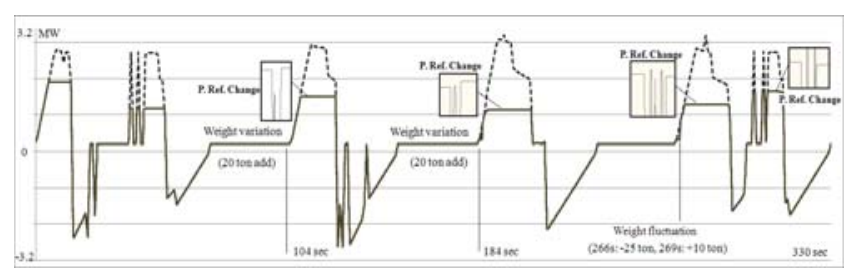

Fig. 10. Power consumption curve and reference signal change with weight variation (South-bound)

By adopting the supercapacitor module in the simulation, the supercapacitor limited the power consumption to the reference power signal. The reference power signal differed at each stage because of the difference in the stored supercapacitor capacity for regenerative energy.

The reference power signal changed when the difference between the expected and real power consumptions was checked (The changed value is shown in the figure by using PSCAD graph). A power consumption variation occurred with additional passengers at a specific time (Figs. 8 and 10), and the developed compensation simulator generated revised reference power signals using the measured data (real power consumption and velocity of the vehicle) for appropriate discharging process.

As mentioned above, the weight can change because of the mobility of passengers and unexpected situations. The situation shown in figure includes an abrupt power consumption fluctuation owing to the weight change. The compensation simulator immediately generated a different reference power signal according to the data obtained from the vehicle.

The reference signal is modified by comparing the measured power consumption with the expected power consumption. Using the reference signal, the discharging process continues, and the SOC variations are shown in Figs. 11 and Fig. 12. The SOC range in the simulation was set to within $20 \%-95 \%$ to protect the lifecycle. The

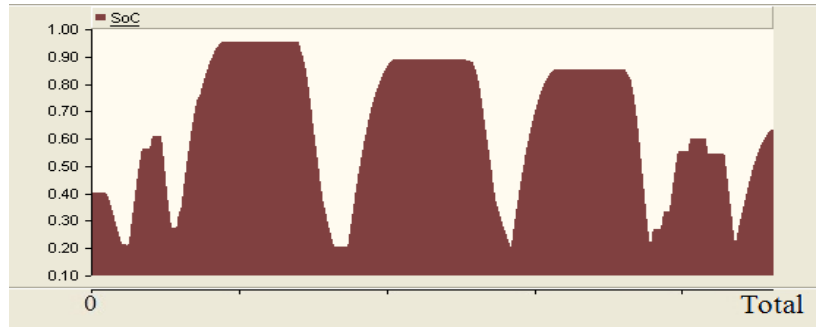

Fig. 11. SOC fluctuation curve for northbound

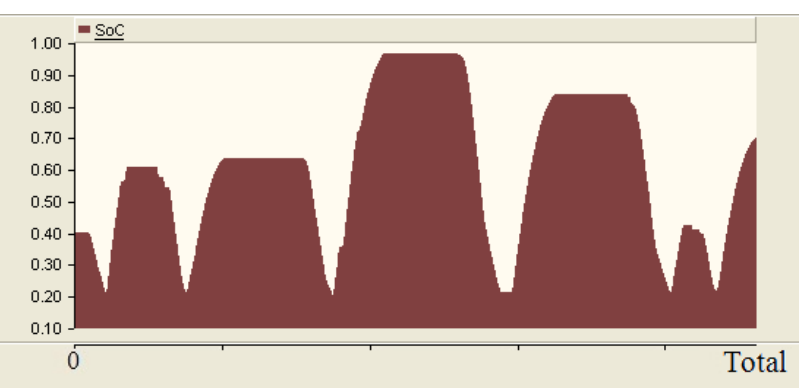

Fig. 12. SOC fluctuation curve for southbound

Table 4. Numerical results of the simulation

\begin{tabular}{|c|c|c|c|c|c|}
\hline $\begin{array}{l}\text { Direc- } \\
\text { tion }\end{array}$ & Case & $\begin{array}{l}\text { Section } \\
\text { (m) }\end{array}$ & $\begin{array}{l}\text { Calculated } \\
\text { weight } \\
\text { difference } \\
\text { (ton) }\end{array}$ & $\begin{array}{c}\text { Weight } \\
\text { error } \\
(\%)\end{array}$ & $\begin{array}{c}\text { Reference } \\
\text { power change } \\
(\mathrm{kW})\end{array}$ \\
\hline \multirow{6}{*}{$\begin{array}{l}\text { North } \\
\text { bound }\end{array}$} & Normal & $2830-3045$ & 0 & 0 & 1705 \\
\hline & Normal & $3282-3392$ & 0 & 0 & 100 \\
\hline & 20t Add. & $3695-3981$ & 19.698 & 1.51 & $670 \gg>680$ \\
\hline & 20t Add. & $4380-4696$ & 39.4 & 1.5 & $850>>925$ \\
\hline & \begin{tabular}{|c|}
$25 t(-)$ \\
And 10t (+)
\end{tabular} & $4940-5080$ & $\begin{array}{c}14.772 \\
\text { And } 24.624\end{array}$ & $\begin{array}{c}1.52 \\
\text { And } 1.5\end{array}$ & $250 \gg>160$ \\
\hline & Normal & $5618-5717$ & 0 & 0 & 445 \\
\hline \multirow{6}{*}{$\begin{array}{l}\text { South } \\
\text { bound }\end{array}$} & Normal & $5895-5720$ & 0 & 0 & 1705 \\
\hline & Normal & $5375-5114$ & 0 & 0 & 970 \\
\hline & 20t Add. & $4940-4700$ & 19.698 & 1.51 & $1225>>1255$ \\
\hline & 20t Add. & $4380-4030$ & 39.4 & 1.5 & $745>>805$ \\
\hline & $\begin{array}{c}25 t(-) \\
\text { And 10t (+) }\end{array}$ & $3695-3375$ & $\begin{array}{c}14.772 \\
\text { And } 24.624\end{array}$ & $\begin{array}{c}1.52 \\
\text { And } 1.5\end{array}$ & $1065>>1015$ \\
\hline & Normal & $3238-3020$ & 0 & 0 & 1375 \\
\hline
\end{tabular}

charging/discharging processes continued within the range.

The calculated weight, error between the calculated and real weight, and reference power at each section are presented in Table 4. The weight error is inevitable due to the existence of voltage fluctuation in the electric system. The revision process is applied by the algorithm; thus, the weight error can be adjusted by the system operator.

\section{Conclusion}

This paper has introduced a weight calculation and update plan for a DC railway system for efficient operation of supercapacitor by utilizing regenerative power. The proposed algorithm was formulated by considering the onboard storage device, which focused on self-utilization of 
regenerative energy. The main purpose of the proposed algorithm is to efficiently utilize the supercapacitor for peak-power reduction using the weight updating process, which considers passenger variation. The entire system was designed to interact with the TPS, which can calculate the entire route and power consumption, as well as the braking power. The railway system and algorithm application were designed using PSCAD, and a verification process was performed by considering a real railway system in Korea. The Gwang-ju railway system is suited for on-board storage system because of its high headway and relatively few operational vehicles. To consider all possible situations, the mentioned weight variation and abnormal situations were simulated. In the simulation, the storage system was successfully compensating during peak-power situation between each phase. Obviously unpredicted situations can be encountered; thus, additional verification process should be considered in future studies.

\section{Acknowledgements}

This research was supported by Basic Science Research Program through the National Research Foundation of Korea(NRF) funded by the Ministry of Education, Science and Technology (2012R1A1A1017114)

This paper was supported by the 'Railroad Technical Research Program 2013' of Korea grant funded by the Korea government(MOLIT) (13RTRP-B067917-01).

\section{References}

[1] A. Adinolfi, R. Lamedica, C. Modesto, A. Prudenzi, and S. Vimercati, "Experimental assessment of energy saving due to trains regenerative braking in an electrified subway line," IEEE Trans. on Power Delivery, Vol. 13, no. 4, pp. 1536-1542, Oct. 1998.

[2] R. J. Hill, Y. Cai, S. H. Case, and M. R. Irving, "Iterative techniques for the solution of complex DCrail traction systems including regenerative braking," IEE Proc. Generation, Transmission, and Distribution, Vol. 143, no. 6, pp. 613-615, Nov. 1996.

[3] Timothy M. Weis, and Adrian Ilinca, "The utility of energy storage to improve the economics of winddiesel power plants in Canada," Renewable Energy, Vol. 33, no. 7, pp. 1544-1557, Jul. 2008.

[4] C. Abbey, and G. Joos, "A stochastic optimization approach to rating of energy storage systems in winddiesel isolated grids," IEEE Trans. on Power Systems, Vol. 24, no. 1, pp. 418-426, Feb. 2009.

[5] F. Barbir, T. Molter, and L. Dalton, "Regenerative fuel cells for energy storage: efficiency and weight trade-offs," IEEE Aerospace and Electronic Systems Magazine, Vol. 20, no. 5, pp. 35-40, Mar. 2005.
[6] S. Samineni, B. K. Johnson, H. L. Hess, and J. D. Law, "Modeling and analysis of a flywheel energy ztorage system for voltage sag correction," IEEE Trans. on Industry Applications, Vol. 42, no. 1, pp. 42-52, Jan.-Feb. 2006.

[7] M. Steiner, M. Klohr, and S. Pagiela, "Energy storage system with ultracaps on board of railway vehicles," in Proceedings of 2007 European Conference on Power Electronics and Applications, Alaborg, Denmark, Sep. 2007.

[8] D. Iannuzzi, and P. Tricoli, "Speed-based state-ofcharge tracking control for metro trains with onboard supercapacitors," IEEE Trans. on Power Electronics, Vol. 27, no. 4, pp. 2129-2140, Apr. 2012.

[9] Y. Diab, P. Venet, H. Gualous, and G. Rojat, "Selfdischarge characterization and modeling of electrochemical capacitor used for power electronics applications," IEEE Trans. on Power Electronics, Vol. 24, no. 2, pp. 510-517, Feb. 2009.

[10] V. Gelman, "Braking energy recuperation," IEEE Vehicular Technology Magazine, Vol. 4, no. 3, pp. 8289, Sep. 2009.

[11] Diego Iannuzzi, Flavio Ciccarelli, and Davide Lauria, "Stationary ultracapacitors storage device for improving energy saving and voltage profile of light transportation networks," Transportation Research Part C: Emerging Technologies, Vol. 21, no. 1, pp. 321-337, Apr. 2012.

[12] Seungmin Jung, Hansang Lee, Kisuk Kim, Hosung Jung, Hyungchul Kim, and Gilsoo Jang, “A Study on Peak Power Reduction using Regenerative Energy in Railway Systems through DC Subsystem Interconnection," Journal of Electrical Engineering and Technology, Vol. 8, no. 5, pp. 1070-1077, Sep. 2013.

[13] Hansang Lee, Seungmin Jung, Yoonsung Cho, Donghee Yoon, and Gilsoo Jang, "Peak Power Reduction and Energy Efficiency Improvement with the Superconducting Flywheel Energy Storage in Electric Railway System," Physica C - Superconductivity and its applications, Vol. 494, pp. 246-249, Nov. 2013.

[14] P. Martin, "Train performance and simulation," in Proceedings of 1999 Winter Simulation Conference, Phoenix, U.S.A, Dec. 1999.

[15] Bih-Yuan $\mathrm{Ku}$, and Jen-Sen, Liu, "Solution of DC power flow for non-grounded traction systems using chain-rule reduction of ladder circuit Jacobian matrices," in Proceedings of 2002 ASME/IEEE Joint Railroad Conference, Washington D.C., U.S.A, Apr. 2002.

[16] Hansang Lee, Hanmin Lee, Changmu Lee, Gilsoo Jang, and Gildong Kim, "Energy storage application strategy on DC electric railroad system using a novel railroad analysis algorithm," Journal of Electrical Engineering and Technology, Vol. 5, no. 2, pp. 228238, Jun. 2010. 


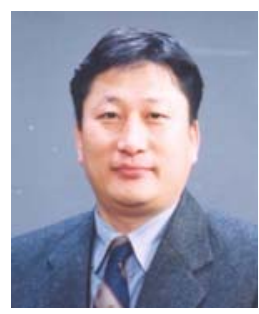

Byungdoo Jung He received Ph. D. degree in Civil Engineering from Osaka City University, Japan. He is presently an Associate Professor of Dept. of Transportation Engineering at Keimyung University.

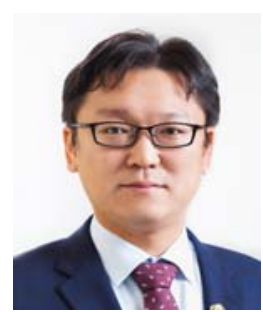

Hyun Kim He received $\mathrm{Ph}$. D. degree in Natural, Biotic and Social environment engineering from Yamanashi University, Japan. His is presently a Director of Dept. of Railway Operation and Technology Research at The Korea Transport Institute.

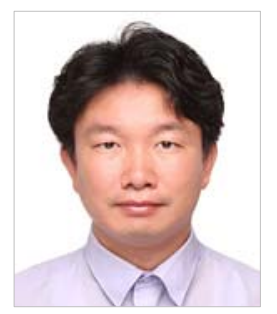

Heechan Kang $\mathrm{He}$ received $\mathrm{Ph}$. D. degree in traffic engineering from Kongju national university, Korea. He is presently a Post-Doc of railway operation technology at The Korea Transport Institute.

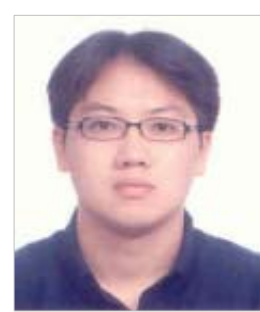

Hansang Lee $\mathrm{He}$ received $\mathrm{Ph}$. D. degree in Electrical Engineering from Korea University, Korea. He is presently an Assistant Professor of School of Electrical \& Railway Engineering at Kyungil University. 